\title{
Agricultured Automatic Drip Irrigation System
}

\author{
${ }^{1}$ Mr. S.G.Galande, ${ }^{2}$ Dr. G.H. Agrawal \\ 1.Research Scholar, RTM Nagpur University, Nagpur \\ 2. Professor, KDK Engineering College, Nagpur
}

\begin{abstract}
Drip irrigation is one of the important area which affects the livelihood of farmers directly. In this paper a survey is carried out far the drip irrigation to be using electronic devices. The drip irrigation system will increase the productivity of the crop. Fertilizers used in irrigation are recommended by various agriculture universities will help the farmer to increase the productivity. Increasing the productivity of different crops soil and water contains are more important. The drip irrigation helps to save the water and increase the productivity of crop. After using embedded system proper mixing of the fertilizer will be possible for improve the productivity of crop. When we use the embedded system more complexity will reduce, but wiring in the field will create problem. Day by day the rainfall goes on decreasing, to save the water for irrigation drip irrigation is important tool in future.
\end{abstract}

Keyword: crop, productivity, drip irrigation, embedded system

\section{Introduction}

Agriculture is an important area, which affects livelihoods of a significant promotion of the country's population apart from ensuring food security. The major problems are rapidly declined growth in productivity of food grains, shrinking water resource, declining soil health. Technology is a prime movement of productivity in agriculture where natural resources are fixed. In agriculture accounts for use of $80 \%$ of annual available fresh water, is save and utilized it is more important. Precision faming is emerging as one of the important areas that can be improving agricultural benefits. India has a great potential to implement such technology. Balanced use of major and micro nutrients to maintain an organic carbon status through soil test based nutrients management is to be formed. An increasing demands of agriculture, industry and population's need, rising levels of pollution. The annual rainfall of 3840 Billions Cubic Meters (BCM), water availability estimates vary between $1123 \mathrm{BCM}$ to $654 \mathrm{BCM}$, providing evaporate transpiration losses (uncertain). Current consumption is estimated at 634 BCM. Future requirements by 2025 as estimated by ministry of water resources are 1093 BCM.

The $60 \%$ of ground water drawn is used for irrigation and mostly through deep tube wells. This over exploitation pattern is increasing ground water pollution and drinking supply to the villages. Effective deployment of technologies, policy and institutional measures are of paramount importance in water management. The uses of new micro-irrigation technologies are to be optimizing water use for crop consumption at crop root zone and soil leaching. Modern tools like embedded system and space technology are highly relevant in monitoring large irrigation commands.

Quality of human life, particularly that of poor and vulnerable sections depends upon natural environment and its endowments, which support their livelihoods and basic needs.[1] Global energy demand is continuing to grow unabated. China and India energy demand is growing at 2 to 3 times that of global annual average of about $1.7 \%$. Distributed energy generation based on locally available energy resources is an option that is increasing being advocated in many countries by introducing innovative policies and financing modalities, as it can provide opportunities for improving access to energy, particularly for dispersed communities in rural and remote areas.

Innovations can reduce the competing demands of water and energy. For example, use of drip irrigation and root irrigation in agriculture can reduce water and energy use in agriculture. Likewise power plants can reduce the water requirements for cooling by using hybrid air-water cooling systems. Engineers must play a more active role in solving problems of urban and rural water utilization.

Agriculture water productivity required is the challenge of sustainability; it is to be addressed satisfactory. The expansion of agriculture land due to increasing demand for food and loss of arable land due to over intensive cultivation is one of the greatest threats to forest, wetlands, mountains and biodiversity. To reduce land degradation through sustainable agriculture practice, such as, high efficiency irrigated systems, integrated pest management and fertilizer use.[2] 


\section{Agriculture Eco Management}

For the management of agriculture to support economic and social development, monitoring agricultural crop conditions, whether and climate, ecosystem, and providing decision support for agricultural planning and policy making are very important. To develop an agriculture field, the eminent persons have underscored the importance of technology implementation in agriculture sector. They have addressed the needs of applying integrated information in this field.[3]

\section{Precision Farming}

Precision farming is system for managing soils and crops to reduce uncertainty of decision for better quality and management. Many researches have been conducted to develop the strategies for site-specific crop management. The focus on variable rate technology for managing spiral variation often failed to deliver significant consistent improvement in crop, profitability, input use efficiency and environment impact. Variation in soil nutrient supply may be most significant within a large field, or among many small fields within a landscape. Precise management improves quality and quantity. More dynamic and real time precision farming approaches are currently being investigated soil crop simulation models are increasingly used to evaluate management options. But this often involves empirical calibration of models to local conditions and then simulating effects of spatial and temporal variation on crop growth. After research, it is analyzed that assessing the potential of precision farming is difficult. In terms of its impact on farmers and in terms of the underlying agronomic principles that hampers faster progress.[4]. Modeling of electromagnetic scattering from soil surfaces has been the object of theoretical and experimental studies for many years. The characterization of soil surfaces is not well understood. Most of the theoretical models describing surface scattering assume ideal soil statistics seldom found in real conditions.[5]

\section{Detection Of Diseases In Citrus Plantations}

A high resolution field-portable spectral radiometer was used for spectral data collection. The spectral range of the spectral radiometer was $350 \mathrm{~nm}$ to $2,500 \mathrm{~nm}$. The spectral reflectance data (Fig.1.) were acquired from the SVC spectral radiometer in visible-near infrared region $(350-2,500 \mathrm{~nm})$ of the electromagnetic spectrum. The resolution of the reflectance data depended on the wavelength of the spectra. The resolution of the spectral reflectance was between $0.9-1.5 \mathrm{~nm}$ for wavelengths from 350 to $980 \mathrm{~nm}$; while, resolution was between 2.1-3.9 $\mathrm{nm}$ for wavelengths from 980 to $2,500 \mathrm{~nm}$. After averaging the spectral reflectance every 25 $\mathrm{nm}$, the spectral reflectance features were reduced from 989 to 86 spectral features.[6]

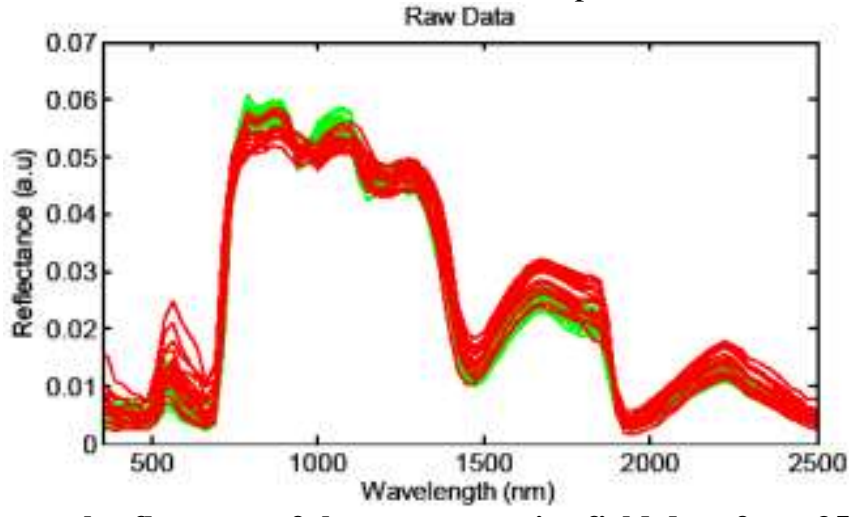

Figure 1. Spectral reflectance of the representative field data from $350-2,500 \mathrm{~nm}$.

\section{Agricultural Productivity}

Agricultural education, extension, and advisory services are a critical means of addressing rural poverty, because such institutions have a mandate to transfer technology, support learning, assist farmers in problem solving, and enable farmers to become more actively embedded in the agricultural knowledge and information system.

The impact of farmer field schooling differed significantly across gender of household head. Farmer Field School participation meant a significant increase in crop productivity for female-headed households in Tanzania, Uganda, and all three countries combined. The increase in crop productivity among females was greater than males for both the absolute value and the percentage increase. Although Kenya had the highest number of women participants (66 percent), there was no significant difference in crop productivity between female- and male-headed participants in Kenya.[7] 
Why Drip Irrigation?

Drip irrigation sends an even, deep supply of water directly to the root zone of the plant without waste or run off. It uses up to $50 \%$ less water than conventional systems, spares plants the stress caused by the wet-dry cycles of overhead watering and minimizes erosion, soil compaction, leaf burn, mold and fungal diseases. Drip irrigation, especially when the line is buried, significantly reduces weeds by watering deeply instead of on the surface (weed seeds have less access to water needed for germination).

Before you install your system, you need to ascertain the flow (how many gallons per minute) you are getting from your main water line, which will help you to determine how many emitters you can run at one time. An easy way to determine this is by running water and measuring the time it takes to fill a bucket. Divide the container size in gallons by the seconds it takes to fill the container, and then multiply the result by 60 . Example: If it takes 40 seconds to fill your 4-gallon bucket, you have $6 \mathrm{GPM}$.

Consider whether your water has a high sediment content or not, so that you can select the proper filter set-up. You should have a vacuum breaker installed at the beginning of your irrigation system to prevent backflow which can contaminate your water supply, especially if you are connected to a well and use a fertilizer injector. Make a scale drawing of your area so that you can visualize the location of buildings, pathways, water sources, and existing planted areas. Grouping plants with similar water requirements will aid in your selection of irrigation parts. Similarly, you should plan whether your planting will be on a slope or not. Drip systems are inexpensive and simple to install. With the installation of a timer, you will provide care-free, regular, even, and convenient watering of your plants.

Subsurface drip irrigation (SDI) offers many advantages as a method of water application and also for controlled release of nutrients into the root-zone. Subsurface drip irrigation for sugarcane is being developed and installed as rapidly as possible at Royal Swaziland Sugar Corporation to replace the less efficient drag-line sprinkler system which has served the industry for many years.

- Increase sucrose yield

- Improve water use efficiency

- Reduce the cost of cane production

- Provide a more even power demand

- Reduce labor inputs

- Provide a more even application of water

- Make water available for expansion elsewhere

- Reduce maintenance costs

- Reduce soil water drainage

- Reduce the number of night shift operations

- Increase the level of automation

Provide an irrigation system that can be operated by management during periods of industrial unrest. In the first year of the project approximately 1550 ha of over-head-irrigated cane at 1.5 meter spacing was converted to SDI with the drip tape placed 1.8 meters apart and cane planted in tramlines, 0.2 meters either side of the tape. The drip line was placed $150 \mathrm{~mm}$ below the surface and discharged 1.6 liters/hour through emitters spaced $920 \mathrm{~mm}$ apart. The cane seed was placed at the same level as the drip tape. Royal Swaziland Sugar Corporation (RSSC) RSSC is collecting data to provide information on the performance of SDI and dragline sprinkler irrigation under sugarcane. The technical knowledge on management and operation of SDI, which is very limited at present at RSSC, will be enhanced through lessons learnt from this project. This report outlines the steps taken in managing SDI at RSSC during the first year, and compares its performance with overhead systems.

\section{Materials and Methods:}

The data comes from forty-six commercial SDI fields in the north-western area of the estate, and thirteen sprinkler-irrigated fields distributed throughout the estate. In these fields, the yields and water use from a plant cane-crop were compared. A conventional statistical comparison of the data was not possible because of the differences in soil types, and to some extent the varieties planted in these fields except for two fields feeding from one pump (pump station 12). The two fields feeding from pump station 12 (1209 and 1212) were on similar soils (T-sets), and planted to the same variety (N19) on tramline spacing of 1.8 meters. One field was irrigated using SDI and the other using sprinkler. The rest of the fields were either on different soil types, or different sugarcane line spacing. The spacing under the sprinkler system was 1.5 meters single rows, while1.8 meters tramline was used in the SDI fields. 


\section{Irrigation Scheduling}

Prior to planting $12 \mathrm{~mm}$ of irrigation was applied so that it could be placed in moist soil, to encourage germination. After planting, water was applied to fill the profile to the field moisture capacity, based on the water holding characteristics (TAM) of the soil. The irrigation was applied in doses of $6 \mathrm{~mm}$ or less to encourage lateral movement, because continuous application encourages vertical movement and increases deep percolation losses. Irrigation scheduling was based on a combined approach using the soil moisture balance calculated from atmospheric demand and auguring to confirm the balance. Factors derived from a comparison of Class A pan and a sugarcane reference evaporation calculated using the Penman Monteith equation(M. McGlinchey, 1994) were used to adjust Class A pan evaporation to an equivalent sugarcane evapotranspiration. These factors depend on the month of cut and the stage of canopy.[8]

\section{Conclusion}

In this review paper drip irrigation is discussed. The drip irrigation is one of the important methods to do the farming where water scarcity is there. By using drip irrigation not only we can increase the productivity but also improve the livelihood of the farmers. We can conclude that by drip irrigation can effectively be implemented using electronic devices.

\section{References}

[1] Dr. K. Kasturirangan, "Science and Technology as Instruments of faster, Sustainable and Inclusive Development" Technorama, The

[2] Institute of Engineers, PP 5-13, volume 61, March 2012

[3] Dr. Arcot Ramachandran, "Technology and the Challenge of Sustainable Development", Technorama, The Institute of Engineers, pp 14-20, volume 61, March 2012.

[4] Lida xu, ning Liang \& Qiong Gao, “An Integrated Approach for Agriculture Eco Management”, IEEE Transaction on system, man, \&

[5] Cybernetics-Part C, Application \& Review, Vol-38, No.4, July 2008.

[6] Acim Dobermann, Simon Blackmore, Simon E. Cook, and Viacheslav I Adamchuk,"Precision faming challenges and Future Directions",

[7] Proceedings of the $4^{\text {th }}$ International Crop Science congress, 26 sep-1Oct 2004.

[8] Franceco Mattia, Malcolm W.J.Dividson, Thuy Le Toon Christophe M.F. Haese, “A Comparison Beteen Soil Roughness Statistics Used in Surface Scattering Models Derived From Mechanical and Laser Profilers", IEEE Transaction on Geo-science and Remote Sensing, Vol 41, No 7, July 2003.

[9] S. Sankaran and R. Ehsani, C. Dima, "Development Of Ground-Based Sensor System For Automated Agricultural Vehicle To Detect

[10] Diseases In Citrus Plantations", paper no. 304, $10^{\text {th }}$ International Conference Precision Agriculture, July 18-21, 2010, Denver, CO

[11] Kristin Davis, Ephraim Nkonya, Edward Kato, Daniel Ayalew Mekonnen, Martins Odendo, Richard Miiro, Jackson Nkuba, "Impact of

[12] Farmer Field Schools on Agricultural Productivity and Poverty in East Africa",

[13] IFPRI Discussion Paper 00992, JUNE 2010, International food policy research Institute.

[14] L.S. NDLOVU, "The Performance Of Subsurface Drip Irrigationat Royal Swaziland Sugar Corporationduring Its First Season", PP-157-

[15] 161, Proc S Afr Sug Technol Ass (2000) 7 Royal Swaziland Sugar Corporation Ltd., Irrigation Dept. P.O. Box 1, Simunye, Swaziland 